\title{
Social Media and the Quality of Subjective Well-Being; Counseling Perspective in Digital Era
}

\author{
Zadrian Ardi ${ }^{1}$, Indah Sukmawati ${ }^{2}$ \\ ${ }^{1}$ Universitas Negeri Padang, Padang, Indonesia Iهzadrian@fip.unp.ac.id \\ ${ }^{2}$ Universitas Negeri Padang, Padang, Indonesia I $\$ i.watsan@gmail.com
}

\begin{abstract}
Various studies in the information technology revealed that there has been a change in the trend of internet use in recent years. Internet users in the world prefer to spend time accessing the internet through the social media. Social media with a variety of platforms provides special communities with their own uniqueness and allows users to share lots of content. The members involves creates a new social community with various phenomena, both positive and negative. Counselors in the millennium era are required to have the insight and knowledge that is qualified to deal with the well being conditions of individuals from activities in social media. Counselors are also required to have specific skills in providing handling with the condition of well being individuals related to the impact of activities on social media.
\end{abstract}

Keywords: Social Media, Internet, Subjective Well Being, Counseling, Digital Era

(C) 20 17. This is an open access article distributed under the Creative Commons Attribution License, which permits unrestricted use, distribution, and reproduction in any medium, provided the original work is properly cited.

\section{Pendahuluan}

Perkembangan teknologi informasi adalah salah satu kemajuan yang dicapai manusia pada abad 21 (Ardi \& Yendi, 2013; Carley \& Spapens, 2017; O’Neill et al., 2017; Romero, Usart, \& Ott, 2015; Sheikh, Sood, \& Bates, 2015). Dalam dekade terakhir, berbagai cabang penelitian dan pengembangan dilakukan berkaitan dengan teknologi ini. Salah satu perkembangan teknologi informasi yang sangat mencolok adalah dinamika internet secara global (Andreassen et al., 2016; Billieux, Maurage, LopezFernandez, Kuss, \& Griffiths, 2015; Prestin, Vieux, \& Chou, 2015; Xiang, Wang, O'Leary, \& Fesenmaier, 2015). Perkembangan pesat ini mengalami peningkatan yang sangat signifikan sejak diluncurkannya Web 2.0 di awal tahun 2000-an (E. W. T. Ngai, Moon, Eric, \& Spencer, 2015).

Terbukanya pengembangan konten dan inovasi di bidang internet telah membuka kesempatan pada media sosial untuk melangkah ke era baru (Benkler, Roberts, Faris, Solow-Niederman, \& Etling, 2015; Lyytinen, Yoo, \& Boland Jr, 2016; Simula, Töllmen, \& Karjaluoto, 2015). Media sosial merupakan wilayah baru pada pemakaian internet yang lebih banyak dituju oleh pengguna internet di seluruh dunia. Kondisi ini membuat media sosial sebagai platform yang menyediakan berbagai kontenkonten tertentu di internet dengan kapasitas besar dan terus berkembang karena sangat aktifnya 
interaksi antar-pengguna di dalamnya (Loeb, 2015; Pittman \& Reich, 2016; Seltzer, Jean, KramerGolinkoff, Asch, \& Merchant, 2015; Thoma et al., 2015).

Studi terbaru menunjukkan bahwa lebih dari 86\% pengguna internet di Amerika Serikat, 79\% pengguna dari Eropa merupakan pengakses aktif dari media sosial dengan konten yang terus berkembang menyesuaikan topik yang ada di dunia (Brooks, 2015). Selain itu, setidaknya lebih dari 2.3 milyar orang dari seluruh dunia terdaftar sebagai pengguna aktif media sosial. Untuk Indonesia sendiri, terdapat lebih dari 139 juta pengguna media sosial aktif yang merupakan $87 \%$ dari pengguna internet di Indonesia (Hasfi, Usman, \& Santosa, 2015), sehingga dapat dikatakan bahwa hampir seluruh pengguna internet di Indonesia memiliki akun media sosial (Alwagait, Shahzad, \& Alim, 2015; Ceron, 2015; Obar \& Wildman, 2015). Angka tersebut membuktikan bahwa kondisi kekuatan media sosial merupakan sesuatu yang tidak dapat dipandang sebelah mata dan membutuhkan perhatian lebih oleh berbagai pihak.

Secara harfiah, istilah media sosial merupakan suatu aktivitas yang dilakukan banyak orang dalam satu lini masa tertentu melalui teknologi berbasis internet, sehingga terdapat suatu koneksi antar pengguna dan membentuk suatu komunitas tertentu (Carley \& Spapens, 2017; Xiang et al., 2015). Pada banyak penelitian, pengembangan media sosial berfokus pada berbagai aktivitas tingkah laku individu yang terlibat di dalamnya, seperti berbagi pengaruh pribadi, membagikan info-info pribadi, saling berbagi identitas dan sebagainya (E. W. Ngai, Tao, \& Moon, 2015a; Roth, Bobko, Van Iddekinge, \& Thatcher, 2016).

Perubahan yang sangat siginifikan terjadi pada penggunaan platform internet di dunia, yang pada awalnya lebih berfokus pada personal blog, official website dan sejenisnya menjadi berfokus pada media sosial dengan kekuatan data yang lebih kuat(Benkler et al., 2015; Carley \& Spapens, 2017; Prestin et al., 2015). Media sosial dapat membangun suatu komunitas baru, mengakses berita terbaru yang dibagikan oleh orang lain pada jaringan platform yang sama atau lintas platform, berbagi pengetahuan baru, terkoneksi dengan teman baru atau membatalkan pertemanan dalam satu komunitas dan banyak hal lainnya, termasuk dalam pengembangan bisnis pribadi, korporat dan pengembangan karir (Ding, Phang, \& Zhang, 2012; E. W. T. Ngai et al., 2015). Penghantaran informasi pribadi maupun perusahaan pada stakeholder sangat mungkin dilakukan melalui media sosial dan bahkan telah dibangun khusus platform sesuai kekhasannya masing-masing (Lyytinen et al., 2016; Seltzer et al., 2015; Thoma et al., 2015). Sehingga hal ini menjadi kekuatan tersendiri bagi media sosial dan manfaatnya bagi individu secara umum.

\section{Hasil dan Pembahasan}

\section{Dinamika Fokus Pengguna Internet dan Media Sosial}

Pada awal perkembangannya, media sosial dibangun dengan asumsi dasar sebagai platform yang berfungsi sebagai "Open Diary" pada akhir 1990-an oleh Bruce dan Susan Abelson (MachinMastromatteo, 2011; Mastromatteo, 2017). Pengembangan ini dimaksudkan agar pengguna platform lain dapat membaca diary yang dituliskan seseorang di satu komunitas yang sama (Bosoteanu, 2013; Kohli \& Gupt, 2015). Dengan perkembangan internet yang sangat signifikan, sehingga pengembangan model dan platform juga terjadi, sehingga pengguna yang awalnya hanya bisa membaca, telah bisa memberikan komentar, seperti berbagi saran dan lain sebagainya.

Pergerakan ekonomi global saat ini juga salah satunya dimotori oleh perkembangan internet (Castells, 2015; Poushter, 2016; Van Bergeijk, 2014), khususnya media sosial. Misalnya jika dahulu sulit untuk memberikan komentar/testimonial terhadap suatu produk yang dipasarkan, melaui media sosial kegiatan tersebut sangat mudah terjadi, sehingga dinamika pasar akan lebih beragam (Leung, Law, Van Hoof, \& Buhalis, 2013; Luo, Zhang, \& Duan, 2013; E. W. Ngai, Tao, \& Moon, 2015b). Selain itu, pergerakan dinamika sosial di masyarakat juga mulai berubah dari forum komunitas konvensional menjadi komunitas online. Dimana individu bisa membuat suatu perkumpulan terbuka 
ataupun rahasia melalui media sosial (Bontcheva \& Rout, 2014; Dekker \& Engbersen, 2014; Hensby, 2017). Pembahasan berbagai hal dapat dilakukan melalui media ini dengan sangat efektif tanpa harus bertemu dan bertatap muka.

Dengan kata lain, media sosial dapat dikatakan sebagai aplikasi berbasis internet yang memungkinkan penggunanya untuk melakukan pertukaran konten-konten umum dan pribadi (Brooks, 2015). Konten-konten di media sosial sangat berbeda dengan konten-konten profesional yang tersedia dalam bentuk koran online, situs official dan semacamnya (Castells, 2015; Van Bergeijk, 2014). Konten pada media sosial bergantung pada kreativitas pengguna dan berkaitan dengan kehidupan pribadi penggunanya.

\section{Media Sosial dan Subjective Well Being}

The discussion will always connect to the introduction by way of the research questions or hypotheses you posed and the literature you reviewed, but it does not simply repeat or rearrange the introduction; the discussion should always explain how your study has moved the reader's understanding of the research problem forward from where you left them at the end of the introduction.

Media sosial diidentifikasi memiliki enam fungsi dasar, diantaranya adalah manajemen identitas pengguna, upaya menemukan ahli di internet, kesadaran konteks, manajemen konten, kesadaran jaringan, dan pertukaran konten, enam hal tersebut didasarkan pada tujuan komunitas internet dalam berbagi konten dan pengetahuan, dan hal tersebut juga didasarkan pada kebutuhan untuk tetap terhubung dengan orang lain melalui jaringan internet (Oh \& Syn, 2015).

Kenyataan tersebut memungkinkan bahwa terjadinya perubahan-perubahan kondisi psikologis dalam diri individu saat melakukan akses ke media sosial. Pada taraf tertentu, media sosial dapat menimbulkan reaksi positif dalam diri individu (Hudson, Roth, Madden, \& Hudson, 2015; Maier, Laumer, Eckhardt, \& Weitzel, 2015; Utz, Schultz, \& Glocka, 2013), seperti perasaan senang saat postingannya direspon oleh orang lain, mendapatkan wawasan penting melalui konten yang dibagikan orang lain, bertemu dengan individu lain dengan minat yang sama, mendapatkan hal-hal baru untuk mengembangkan diri, serta hal-hal positif lainnya. Namun, media sosial juga dapat mengganggu kondisi diri individu sehari-hari, terutama kondisi yang berkaitan dengan aspek psikologis individu (Maier et al., 2015).

Penggunaan media sosial yang berlebihan dapat memunculkan kondisi kecanduan pada diri individu. Penelitian menunjukkan bahwa hanya $40 \%$ dari waktu karyawan yang digunakan untuk fokus pada pekerjaan. Lebih dari $28 \%$ waktu karyawan per harinya habis digunakan untuk menggunakan/mengakses media sosial disela-sela pekerjaan, dan apabila karyawan telah mengakses media sosial tersebut, maka perlu waktu 25 menit untuk kembali fokus pada pekerjaannya (Brooks, 2015). Berdasarkan hasil survey Cengage Learning (2014) mengungkapkan bahwa lebih dari 59\% pelajar mengakses media sosial pada saat pembelajaran berlangsung, sehingga hal ini berakibat pada tidak fokusnya siswa mengikuti pembelajaran, kurangnya partisipasi dalam kegiatan diskusi, kurang fokus dalam pengerjaan tugas, dan terganggunya proses transfer dalam pembelajaran kepada siswa (Jin, Liu, \& Austin, 2014; Perloff, 2014; Uche \& Obiora, 2016).

Kondisi adiktif lain yang berpengaruh pada kesehatan mental individu, khususnya pada subjective well being adalah ketergantungan pada kegiatan dan aktivitas di media sosial. Misalnya kegiatan posting konten, komentar, berbagi kegiatan pribadi dan lain sebagainya. Perubahan mood individu karena komentar-komentar dari media sosial juga akan mempengaruhi kondisi well being (Best, Manktelow, \& Taylor, 2014; Sengupta \& Chaudhuri, 2014; Whittaker \& Kowalski, 2015). Keinginan untuk diperhatikan juga ditunjukkan oleh pengguna media sosial, seperti membagikan kisah-kisah pribadi kepada publik dan berharap adanya respon yang diharapkan dari orang lain (Naslund, Grande, Aschbrenner, \& Elwyn, 2014; Uche \& Obiora, 2016). Sehingga dapat dikatakan 
bahwa media sosial merupakan suatu teknologi yang memiliki sisi positif dan negatif sehingga apabila individu telah berada pada taraf adiksi, maka akan mempengaruhi kondisi subjective well beingnya.

\section{Tantangan Konselor di Era Millenial}

Perkembangan teknologi memberikan berbagai kemudahan dalam jenis-jenis layanan kemanusiaan, termasuk dalam proses pelayanan konseling (Ardi, 2014; Ardi, Ibrahim, \& Said, 2012; Daharnis \& Ardi, 2016; Restu, Yusri, \& Ardi, 2013). Dengan hadirnya internet, pelayanan konseling dapat ditawarkan melalui jaringan (daring) kepada klien tanpa harus bertatap muka (face to face). Berbagai permasalahan klien juga dapat berasal dari penggunaan internet dan hal-hal lain yang berkaitan dengannya, termasuk dalam penggunaan media sosial (Cundy, 2014; Dowling \& Rickwood, 2013; Richards \& Viganó, 2013). Konselor sebagai pendidik dan pekerja sosial mempunyai tantangan tersendiri dalam memberikan pelayanan, terlebih pada era millenial dengan sasaran layanan generasi digital (digital native).

Tantangan konselor tersebut dapat berupa kondisi maladjusment yang muncul dari penggunaan internet yang berlebihan, permasalahan sosial yang bersumber dari internet, maupun kecanduankecanduan lain yang muncul (Karvinen et al., 2017; Whittaker \& Kowalski, 2015). Kasus lain yang dapat muncul adalah maraknya perilaku cyberbullying di berbagai platform media sosial sehingga memunculkan efek lebih lanjut yang dapat merugikan individu maupun orang-orang disekitarnya (Yanti, Erlamsyah, Zikra, \& Ardi, 2013).

Kenyataan-kenyataan tersebut menuntut konselor untuk tanggap terhadap perkembangan teknologi informasi dan berbagai kasus yang muncul karena teknologi ini. Selain itu, konselor juga diharapkan memiliki berbagai wawasan, pengetahuan, nilai dan sikap yang dapat dijadikan referensi yang tepat dalam penanganan klien dengan kasus berkenaan pengaruh teknologi informasi (Ardi \& Yendi, 2017).

\section{Kesimpulan}

Inovasi dan perkembangan teknologi informasi telah membuka peluang bagi pertumbuhan berbagai platform media sosial di dunia (Ruths \& Pfeffer, 2014). Media sosial merupakan dunia baru yang banyak dituju oleh berbagai pengguna di dunia untuk berbagi konten-konten tertentu dan berinteraksi satu sama lain sehingga membentuk suatu komunitas digital (Bonilla \& Rosa, 2015; Habibi, Laroche, \& Richard, 2014). Pada taraf tertentu, media sosial dapat menciptakan reaksi positif dalam diri individu, seperti mendapatkan wawasan penting melalui konten yang dibagikan orang lain, bertemu dengan individu lain dengan minat yang sama, mendapatkan hal-hal baru untuk mengembangkan diri, serta hal-hal positif lainnya. Namun, media sosial juga dapat mengganggu kondisi diri individu sehari-hari, terutama kondisi yang berkaitan dengan aspek psikologis individu. Berbagai permasalahan yang muncul dari media sosial menuntut konselor untuk tanggap terhadap perkembangan teknologi informasi diharapkan memiliki berbagai wawasan, pengetahuan, nilai dan sikap yang dapat dijadikan referensi yang tepat dalam penanganan klien dengan kasus berkenaan pengaruh teknologi informasi.

\section{Referensi}

Alwagait, E., Shahzad, B., \& Alim, S. (2015). Impact of social media usage on students academic performance in Saudi Arabia. Computers in Human Behavior, 51, 1092-1097.

Andreassen, C. S., Billieux, J., Griffiths, M. D., Kuss, D. J., Demetrovics, Z., Mazzoni, E., \& Pallesen, S. ale. (2016). The relationship between addictive use of social media and video games and symptoms of psychiatric disorders: A large-scale cross-sectional study. Psychology of Addictive Behaviors, 30(2), 252. 
Ardi, Z. (2014). Cita-cita Perkerjaan dan Pilihan Peminatan Siswa Sekolah Menengah Atas Negeri di Sumatera Barat.

Ardi, Z., Ibrahim, Y., \& Said, A. (2012). Capaian Tugas Perkembangan Sosial Siswa dengan Kelompok Teman Sebaya dan Implikasinya terhadap Program Pelayanan Bimbingan dan Konseling. Konselor, 1(2).

Ardi, Z., \& Yendi, F. M. (2013). Konseling Online: Sebuah Pendekatan Teknologi Dalam Pelayanan Konseling. Jurnal Konseling Dan Pendidikan, 1(1), 1-5.

Ardi, Z., \& Yendi, F. M. (2017). Students Attitude Towards LGBTQ; the Future Counselor Challenges. Jurnal Konseling Dan Pendidikan, 5(2), 74-79.

Benkler, Y., Roberts, H., Faris, R., Solow-Niederman, A., \& Etling, B. (2015). Social mobilization and the networked public sphere: Mapping the SOPA-PIPA debate. Political Communication, 32(4), 594624 .

Best, P., Manktelow, R., \& Taylor, B. (2014). Online communication, social media and adolescent wellbeing: A systematic narrative review. Children and Youth Services Review, 41, 27-36.

Billieux, J., Maurage, P., Lopez-Fernandez, O., Kuss, D. J., \& Griffiths, M. D. (2015). Can disordered mobile phone use be considered a behavioral addiction? An update on current evidence and a comprehensive model for future research. Current Addiction Reports, 2(2), 156-162.

Bonilla, Y., \& Rosa, J. (2015). \# Ferguson: Digital protest, hashtag ethnography, and the racial politics of social media in the United States. American Ethnologist, 42(1), 4-17.

Bontcheva, K., \& Rout, D. (2014). Making sense of social media streams through semantics: a survey. Semantic Web, 5(5), 373-403.

Bosoteanu, I. C. (2013). Impactul social media asupra comunicarii politice. Sociologie Romaneasca, 11(1), 8.

Brooks, S. (2015). Computers in Human Behavior Does personal social media usage affect efficiency and well-being ? Computers in Human Behavior, 46, 26-37. https://doi.org/10.1016/j.chb.2014.12.053

Carley, M., \& Spapens, P. (2017). Sharing the world: sustainable living and global equity in the 21st century. Routledge.

Castells, M. (2015). Networks of outrage and hope: Social movements in the Internet age. John Wiley \& Sons.

Ceron, A. (2015). Internet, news, and political trust: The difference between social media and online media outlets. Journal of Computer-Mediated Communication, 20(5), 487-503.

Cundy, L. (2014). Love in the Age of the Internet: Attachment in the Digital Era. Karnac Books.

Daharnis, D., \& Ardi, Z. (2016). THE COMPATIBILITY STUDENT CHOICE OF UNIVERSITY MAJORING; A PRELIMINARY STUDIES. GUIDENA: Jurnal Ilmu Pendidikan, Psikologi, Bimbingan Dan Konseling, 6(1), 101-109.

Dekker, R., \& Engbersen, G. (2014). How social media transform migrant networks and facilitate migration. Global Networks, 14(4), 401-418.

Ding, Y., Phang, C. W., \& Zhang, C. (2012). The Influence Of User Interaction And Participation In Social Media On The Consumption Intention Of Niche Products. 
Dowling, M., \& Rickwood, D. (2013). Online counseling and therapy for mental health problems: A systematic review of individual synchronous interventions using chat. Journal of Technology in Human Services, 31(1), 1-21.

Habibi, M. R., Laroche, M., \& Richard, M.-O. (2014). The roles of brand community and community engagement in building brand trust on social media. Computers in Human Behavior, 37, 152-161.

Hasfi, N., Usman, S., \& Santosa, H. P. (2015). Refleksi Peran Media Sosial dalam Demokrasi dan Pemilu di Berbagai Negara: Bagaimana dengan Perannya dalam Proses Demokratisasi di Indonesia? Komunikasi Massa Jurnal, 8(2), 203.

Hensby, A. (2017). Open networks and secret Facebook groups: exploring cycle effects on activists' social media use in the 2010/11 UK student protests. Social Movement Studies, 16(4), 466-478.

Hudson, S., Roth, M. S., Madden, T. J., \& Hudson, R. (2015). The effects of social media on emotions, brand relationship quality, and word of mouth: An empirical study of music festival attendees. Tourism Management, 47, 68-76.

Jin, Y., Liu, B. F., \& Austin, L. L. (2014). Examining the role of social media in effective crisis management: The effects of crisis origin, information form, and source on publics' crisis responses. Communication Research, 41(1), 74-94.

Karvinen, K. H., Balneaves, L., Courneya, K. S., Perry, B., Truant, T., \& Vallance, J. (2017). Evaluation of Online Learning Modules for Improving Physical Activity Counseling Skills, Practices, and Knowledge of Oncology Nurses. In Oncology nursing forum (Vol. 44, p. 729).

Kohli, S., \& Gupt, A. (2015). Identification of Human Behavioral Traits Using Social Media.

Leung, D., Law, R., Van Hoof, H., \& Buhalis, D. (2013). Social media in tourism and hospitality: A literature review. Journal of Travel \& Tourism Marketing, 30(1-2), 3-22.

Loeb, S. (2015). Social media makes global urology meetings truly global. BJU International, 115(2), 175-175.

Luo, X., Zhang, J., \& Duan, W. (2013). Social media and firm equity value. Information Systems Research, 24(1), 146-163.

Lyytinen, K., Yoo, Y., \& Boland Jr, R. J. (2016). Digital product innovation within four classes of innovation networks. Information Systems Journal, 26(1), 47-75.

Machin-Mastromatteo, J.-D. (2011). Studying the Influence (or Mutual Shaping) of Social Networks in a Learning Experience: Methods for a Pilot Study.

Maier, C., Laumer, S., Eckhardt, A., \& Weitzel, T. (2015). Giving too much social support: social overload on social networking sites. European Journal of Information Systems, 24(5), 447-464.

Mastromatteo, J. D. M. (2017). The Mutual Shaping of Social Networks, Learning Experiences, and Literacies: The Methods Revisited. Qualitative and Quantitative Methods in Libraries, 2(2), 195-205.

Naslund, J. A., Grande, S. W., Aschbrenner, K. A., \& Elwyn, G. (2014). Naturally occurring peer support through social media: the experiences of individuals with severe mental illness using YouTube. PLOS One, 9(10), e110171.

Ngai, E. W. T., Moon, K. K., Eric, S. S. L., \& Spencer, S. K. C. (2015). Social media models , technologies, and applications. https://doi.org/10.1108/IMDS-03-2015-0075 
Ngai, E. W., Tao, S. S., \& Moon, K. K. (2015a). Social media research: Theories, constructs, and conceptual frameworks. International Journal of Information Management, 35(1), 33-44.

Ngai, E. W., Tao, S. S., \& Moon, K. K. (2015b). Social media research: Theories, constructs, and conceptual frameworks. International Journal of Information Management, 35(1), 33-44.

Obar, J. A., \& Wildman, S. S. (2015). Social media definition and the governance challenge: An introduction to the special issue.

Oh, S., \& Syn, S. Y. (2015). Motivations for Sharing Information and Social Support in Social Media : A Comparative Analysis of Facebook, Twitter, Delicious, YouTube, and Flickr. JOURNAL OF THE ASSOCIATION FOR INFORMATION SCIENCE AND TECHNOLOGY, 66(April), 2045-2060. https://doi.org/10.1002/asi

O’Neill, B. C., Kriegler, E., Ebi, K. L., Kemp-Benedict, E., Riahi, K., Rothman, D. S., ... Kok, K. (2017). The roads ahead: narratives for shared socioeconomic pathways describing world futures in the 21st century. Global Environmental Change, 42, 169-180.

Perloff, R. M. (2014). Social media effects on young women's body image concerns: Theoretical perspectives and an agenda for research. Sex Roles, 71(11-12), 363-377.

Pittman, M., \& Reich, B. (2016). Social media and loneliness: Why an Instagram picture may be worth more than a thousand Twitter words. Computers in Human Behavior, 62, 155-167.

Poushter, J. (2016). Smartphone ownership and internet usage continues to climb in emerging economies. Pew Research Center, 22.

Prestin, A., Vieux, S. N., \& Chou, W. S. (2015). Is online health activity alive and well or flatlining? Findings from 10 years of the Health Information National Trends Survey. Journal of Health Communication, 20(7), 790-798.

Restu, Y., Yusri, Y., \& Ardi, Z. (2013). Studi Tentang Perilaku Agresif Siswa di Sekolah. Konselor, 2(1).

Richards, D., \& Viganó, N. (2013). Online counseling: A narrative and critical review of the literature. Journal of Clinical Psychology, 69(9), 994-1011.

Romero, M., Usart, M., \& Ott, M. (2015). Can serious games contribute to developing and sustaining 21st century skills? Games and Culture, 10(2), 148-177.

Roth, P. L., Bobko, P., Van Iddekinge, C. H., \& Thatcher, J. B. (2016). Social media in employeeselection-related decisions: A research agenda for uncharted territory. Journal of Management, 42(1), 269-298.

Ruths, D., \& Pfeffer, J. (2014). Social media for large studies of behavior. Science, 346(6213), 1063-1064.

Seltzer, E. K., Jean, N. S., Kramer-Golinkoff, E., Asch, D. A., \& Merchant, R. M. (2015). The content of social media's shared images about Ebola: a retrospective study. Public Health, 129(9), 1273-1277.

Sengupta, A., \& Chaudhuri, A. (2014). Simply having a social media profile does not make teens more likely to be bullied online. Demographics and online behavior play a larger role. LSE American Politics and Policy.

Sheikh, A., Sood, H. S., \& Bates, D. W. (2015). Leveraging health information technology to achieve the "triple aim" of healthcare reform. Journal of the American Medical Informatics Association, 22(4), 849-856. 
Simula, H., Töllmen, A., \& Karjaluoto, H. (2015). Facilitating innovations and value co-creation in industrial B2B firms by combining digital marketing, social media and crowdsourcing. In Marketing Dynamism \& Sustainability: Things Change, Things Stay the Same... (pp. 254-263). Springer.

Thoma, B., Sanders, J. L., Lin, M., Paterson, Q. S., Steeg, J., \& Chan, T. M. (2015). The social media index: measuring the impact of emergency medicine and critical care websites. Western Journal of Emergency Medicine, 16(2), 242.

Uche, A. O., \& Obiora, A. V. (2016). Social Media Typology, Usage and Effects on Students of Nigerian Tertiary Institutions. International Journal of Innovative Research and Development, 5(8).

Utz, S., Schultz, F., \& Glocka, S. (2013). Crisis communication online: How medium, crisis type and emotions affected public reactions in the Fukushima Daiichi nuclear disaster. Public Relations Review, 39(1), 40-46.

Van Bergeijk, P. A. (2014). Economic diplomacy and the geography of international trade. Edward Elgar Publishing.

Whittaker, E., \& Kowalski, R. M. (2015). Cyberbullying via social media. Journal of School Violence, $14(1), 11-29$

Xiang, Z., Wang, D., O'Leary, J. T., \& Fesenmaier, D. R. (2015). Adapting to the internet: trends in travelers' use of the web for trip planning. Journal of Travel Research, 54(4), 511-527.

Yanti, S., Erlamsyah, E., Zikra, Z., \& Ardi, Z. (2013). Hubungan Antara Kecemasan Dalam Belajar Dengan Motivasi Belajar Siswa. Konselor, 2(1). 